\title{
Attitudes of Pharmacy Students Toward Bearing a Gun on Campus
}

\author{
Yelena Sahakian \\ University of Chicago Medicine
}

\author{
Ateequr Rahman \\ Rosalind Franklin University of Medicine and Science
}

In the United States, the number of gun-violence-related injuries and deaths have significantly increased over the last 10-20 years, especially on school campuses. This study assesses the opinion of pharmacy students at Rosalind Franklin University of Medicine and Science regarding bearing a gun on campus. The participants were administered an informed consent along with an anonymous online survey. A total of 153 students participated in the study. While they supported students bearing guns on campus for self-defense, they disagreed with faculty doing so. The majority supported having armed officers on campus and obtaining mental health screenings for gun ownership. The majority across different age groups, race, sex, ideology, and year in pharmacy school believed that the US government was not doing enough to address the gun violence issue. Policymakers, colleges of pharmacy, and various practice settings should have procedures in place to address gun violence more explicitly.

Keywords: campus, gun violence, pharmacy, student opinion

\section{INTRODUCTION}

The United States of America was built on the principles of freedom, equality, and justice. As our forefathers drafted the ideals of this country, they included the second amendment which states, "the right of people to bear arms, shall not be infringed." The Second Amendment has been a topic of controversy with recent events of mass shootings and increasing amounts of gun violence. Many people believe that there should be more restrictions on the accessibility of guns due to these events and trends. The gun culture in the United States was born from long standing views relating to gun ownership, particularly for protection, but also as items for collection or for hobbies. Some members of society still believe in the feeling of safety from owning or carrying their own firearm, but others believe that this makes them more unsafe. This topic has been thoroughly investigated, and two-thirds of Americans believe that guns should not be carried in public places like college campuses, schools, religious settings, and malls. (Wolfson, Teret, Azrael, \& Miller, 2017)

Women are more likely than men to believe that assault weapons should be banned and are also more likely to believe that teachers and professors should be allowed to carry a registered weapon in schools.(Lewis et al., 2016) A majority of the participants in that study also believe that there should be more security precautions in schools. The top four factors contributing to gun violence are thought to be a 
decline in parenting and family values, gang involvement, bullying, and the fact that guns are easy to obtain in the US.

In the United States, the number of gun-violence-related injuries and deaths have significantly increased over the last 10-20 years. Gun violence is a leading cause of premature death in the US. Each year, guns kill more than 38,000 people and cause nearly 85,000 injuries. ("Gun Violence," n.d.) In comparison to other countries, the United States is one of the top-ranking countries with the most gun-related deaths at a staggering average of 4.43 people per 100,000 in 2017.(Aizenman, 2018) Despite the rise in gun violence over recent years, there has been some decrease in gun-related deaths and injuries in 2018 as compared to 2017 data.(Mascia, 2019) However, the numbers can be slightly overestimated, as it does not include suicides, which accounts for a significant number of gun-related deaths.

Countries such as Japan, Norway, the United Kingdom, and Australia have very low rates of gunrelated injuries and deaths.(Weller, 2018) Japan has strict laws for obtaining firearms, with rarely more than 10 gun-related deaths per year. In order to own a firearm in Japan, one must attend an all-day class, pass a written test, and achieve at least a 95\% accuracy during a shooting range-test. In addition, one also has to pass a mental-health exam and background check, which needs to be repeated every three years. Norway and the United Kingdom also have strict laws on gun control, which includes background checks, hindrances to obtaining guns, such as specifying the reason for purchase, furnishing a good character certification, safe storage requirements and mental health exams.

One of the first things routinely discussed in the aftermath of a mass shooting is the mental instability of the shooter. In some ways, it can be unjust to generalize individuals with mental illness as most likely to cause such violence. In fact, those who are mentally ill are more likely to be a victim of violence than the perpetrator. According to the National Alliance on Mental Illness (NAMI), the research on gun violence related to mental health is dependent on specific factors, which include concurrent abuse of alcohol or illegal drugs, past history of violence, young age and male gender, and untreated psychosis.("Violence and Gun Reporting Laws," 2019) The best way to reduce risk is through treatment of mental illness, making policies and programs available to people involved in acts of violence, and provide access to mental health services. Creating more federal or state gun laws based on mental illness could reduce barriers to those seeking help and treatment. It is important for the government to fund programs focused on early identification, early intervention, and evidence-based mental health treatments.

Some of the most devastating mass shooting in US history were ones on school campuses. Two of the most deadly shootings were those at Sandy Hook Elementary School in 2012 with 26 victims, and at Virginia Polytechnic Institute (Virginia Tech) in 2007 with 32 victims.(Keneally, 2019)'("Virginia Tech shooting leaves 32 dead," 2011) A federal policy named "Now is the Time," which was developed by the Obama administration, called for closing background check loopholes to keep guns out of dangerous hands and banning military assault weapons and high capacity magazines while limiting ammunition rounds to 10. The policy also stressed the importance of making schools safer and increasing access to mental health services. (Now is the Time, 2013)

A survey of more than 10,000 undergraduate students revealed that $4.3 \%$ of the students routinely carried a working firearm at college. (Miller, Hemenway, \& Wechsler, 2002) Some of them reported being threatened with a gun at school, and the majority said that they had the gun for protection - a behavior that puts themselves and others at risk for injury and death.

Public opinion overall, and of those who own firearms, suggests that less than 1in 3 US adults supported carrying a gun in public places, including restaurants, schools, bars, sports stadiums, retail stores, and other venues.(Wolfson et al., 2017) Those that own a gun are more likely to support carrying a gun in public places than non-owners. Overall, the support for carrying a gun in public was lowest for schools, bars, and sports stadiums indicating that most Americans support the idea of restricting guns in public places.

Another study on beliefs about carrying handguns on college campuses and factors leading to gun violence showed that half the participants believed that assault weapons should be banned, and that teachers should be allowed to carry a registered a handgun on campus. Twice as many females supported the idea as compared to males with no differences amongst various ethnic groups. The factors contributing to gun violence were decline in parenting and family values, gang involvement, bullying, easy access to guns, and 
household gun ownership.(Lewis et al., 2016)'(Bergstein, Hemenway, Kennedy, Quaday, \& Ander, 1996) Males are more likely to own guns as opposed to females. However, religion, political affiliation, race, and age have not been found to have a role in student opinions on gun violence. (Lewis \& Huynh, 2017)

The literature review brings an interesting insight into factors associated with gun violence. As we can see, the opinion about the importance of public safety and avoidance of gun violence is relatively uniform. However, multiple factors come into play when examining student opinions. These factors are not consistent across different US states and graduate schools, and no study was found to comprehensively address the opinion of pharmacy schools on this topic. It is important to study this research question as it pertains to graduate schools in general, and pharmacy schools in particular, to gain a better insight into this matter. The aim of the current study is to examine pharmacy student opinion about gun violence at Rosalind Franklin University of Medicine and Science College of Pharmacy.

\section{METHODS}

This study looked at attitudes of pharmacy students toward gun violence on campus. We hypothesized that there is a difference in student opinions based on gender, race, age, and political affiliation, as well as household gun ownership status. Apart from the variables mentioned above, we also examined the opinion based on pharmacy student class affiliation (P1, P2, P3, or P4) and other variables.

Research participants were administered an online survey with an informed consent letter attached to it, informing them that their participation was voluntary. The respondents were not identified with their responses. The survey consisted of a 10-question demographic part asking about gender, age, class affiliation (pharmacy school years 1-4), race, household gun ownership, political affiliation, etc. The rest of the survey asked 17 opinion questions with Likert-scale responses. The survey instrument was tested for ambiguity and for understanding of the words used. An apriori grade level of 9 was set up, and the readability of the survey was found to be at a grade level of 7.2. The reliability of the survey on Cronbach's coefficient was 0.95 on a test-retest method. The study was approved by the Rosalind Franklin University Institutional Review Board (IRB).

\section{RESULTS}

The majority of the students were in the age range of 20 to 25 years old (66.7\%) and were of Caucasian (45\%) and Asian (31.5\%) origin. Classes P1 through P4 and both genders were almost evenly distributed amongst the participants. The majority of the students were not trained on firearm possession (57.5\%) and did not own a gun (86.9\%); however, a member of their family did own a gun (60.0\%). An overwhelming majority of the students $(98.0 \%)$ never carried a gun on campus and identified themselves as liberal $(62.1 \%)$ (Table 1).

TABLE 1

DEMOGRAPHICS

\begin{tabular}{|l|l|l|}
\hline Variables & Frequency & Percentage \\
\hline Age & & \\
$20-25$ & 102 & 66.7 \\
$26-30$ & 36 & 23.5 \\
$31-35$ & 9 & 5.9 \\
36 and above & 6 & 3.9 \\
\hline Gender & & \\
Male & 82 & 53.6 \\
Female & 71 & 46.4 \\
\hline
\end{tabular}




\begin{tabular}{|l|l|l|}
\hline Year & 36 & 23.5 \\
P1 & 43 & 28.2 \\
P2 & 38 & 24.8 \\
P3 & 36 & 23.5 \\
P4 & 69 & \\
\hline Race & 21 & 45.0 \\
Caucasian & 15 & 13.7 \\
Hispanic & 48 & 9.8 \\
African American & & 31.5 \\
Asian & 44 & \\
\hline Past family gun ownership status & 109 & 28.8 \\
Yes & 58 & 71.2 \\
No & 95 & \\
\hline Ideology & & 37.9 \\
Conservative & 3 & 62.1 \\
Liberal & 150 & \\
\hline Carrying a weapon at school & & 2.0 \\
Yes & 65 & 98.0 \\
No & 88 & \\
\hline Training on firearm possession & & 42.5 \\
Yes & 20 & 57.5 \\
no & 133 & 13.0 \\
\hline Current gun ownership status & & 86.9 \\
Yes & & \\
No & & 60.0 \\
\hline Current family gun ownership & & 40.0 \\
status & & \\
Yes & & \\
No & & \\
\hline
\end{tabular}

The majority of students were not scared or anxious about gun violence occurring on campus. The students believed they should be allowed to carry guns on campus for self-defense, while they disagreed on professors carrying guns. Most students felt safe on campus and did not find it necessary to have security measures in place, however, they agreed on having armed officers on campus. The majority favored banning assault weapons and large capacity clips. They also agreed to requiring a mental health exam and reporting its status for owning a gun. An overwhelming majority across age, race, sex, ideology, and year in pharmacy school believed that the US government was not doing enough to address the gun violence issue. Students strongly believed that universal background checks should be mandated to purchase a gun. In addition, most students believed that community pharmacy practice settings were unsafe, while hospital pharmacy settings were considered a safer environment (Table 2). 
TABLE 2

STUDENT OPINIONS

\begin{tabular}{|l|l|}
\hline Survey Opinion Questions & Mean ( \pm SD) \\
\hline I am scared when I am on campus that gun violence may occur. & $1.99( \pm 1.50)$ \\
\hline I believe that professors should be able to carry registered guns for self-defense. & $1.99( \pm 2.81)$ \\
\hline I believe that students should be able to carry registered guns for self-defense. & $3.99( \pm 1.29)$ \\
\hline I believe that campus security should be able to carry registered guns for self-defense. & $4.27( \pm 0.90)$ \\
\hline I feel anxious that gun violence will occur on campus. & $2.84( \pm 1.67)$ \\
\hline I believe that to own a gun there should be universal background checks. & $4.05( \pm 1.21)$ \\
\hline I believe that assault weapons should be banned. & $3.15( \pm 1.80)$ \\
\hline I believe that there should be armed officers on campus. & $4.12( \pm 1.41)$ \\
\hline I believe that large capacity clips should be banned. & $4.56( \pm 0.85)$ \\
\hline I believe that states should be report mental health status for those obtaining guns. & $4.33( \pm 1.13)$ \\
\hline I believe that in order to obtain a gun a mental health exam should be performed. & $2.44( \pm 1.77)$ \\
\hline I believe that security measures should be in place on campus. & $1.45( \pm 2.02)$ \\
\hline I believe that the US government is doing enough to address the issue of gun violence. & $1.13( \pm 0.53)$ \\
\hline I feel safe on campus. & $3.44( \pm 1.73)$ \\
\hline I believe the practice of pharmacy is safe from gun violence. & $1.78( \pm 1.40)$ \\
\hline I believe the practice of pharmacy in a community setting is safe from gun violence. & $1.61( \pm 0.85)$ \\
\hline I believe the practice of pharmacy in a hospital setting is safe from gun violence. & $3.90( \pm 1.35)$ \\
\hline
\end{tabular}

There was a significant difference amongst the students' opinion toward their perception of safety, anxiety, and ability to carry a gun on campus. Significant differences were also found in the student perception regarding banning assault weapons and large capacity clips. Mental health exam requirements for procuring and owning a gun were significantly different amongst various factors, such as student age, gender, race, ideology, and gun ownership status. There was a significant difference amongst various student groups regarding the role of the US government in addressing the issue of gun violence (Table 3).

TABLE 3

\section{STUDENT OPINIONS ABOUT BEARING GUN ON CAMPUS BY DEMOGRAPHIC VARIABLES}

\begin{tabular}{|l|l|l|l|l|l|}
\hline Question & $\begin{array}{l}\text { Gender } \\
(\boldsymbol{p})\end{array}$ & $\begin{array}{l}\text { Age } \\
(\boldsymbol{p})\end{array}$ & $\begin{array}{l}\text { Race } \\
(\boldsymbol{p})\end{array}$ & $\begin{array}{l}\text { Ideology } \\
(\boldsymbol{p})\end{array}$ & $\begin{array}{l}\text { Gun } \\
\text { Ownership } \\
(\boldsymbol{p})\end{array}$ \\
\hline $\begin{array}{l}\text { I am scared when I am on campus that } \\
\text { gun violence may occur. }\end{array}$ & 0.001 & 0.001 & 0.001 & 0.000 & 0.001 \\
\hline $\begin{array}{l}\text { I believe that professors should be able } \\
\text { to carry registered guns for self- } \\
\text { defense. }\end{array}$ & 0.001 & 0.001 & 0.001 & 0.001 & 0.001 \\
\hline $\begin{array}{l}\text { I believe that students should be able to } \\
\text { carry registered guns for self-defense. }\end{array}$ & 0.001 & 0.001 & 0.001 & 0.001 & 0.001 \\
\hline $\begin{array}{l}\text { I believe that campus security should } \\
\text { be able to carry registered guns for } \\
\text { self-defense. }\end{array}$ & 0.001 & 0.001 & 0.001 & 0.032 & 0.001 \\
\hline $\begin{array}{l}\text { I feel anxious that gun violence will } \\
\text { occur on campus. }\end{array}$ & 0.001 & 0.001 & 0.001 & 0.016 & 0.001 \\
\hline
\end{tabular}




\begin{tabular}{|l|l|l|l|l|l|}
\hline $\begin{array}{l}\text { I believe that to own a gun there should } \\
\text { be universal background checks. }\end{array}$ & 0.027 & 0.001 & 0.001 & 0.000 & 0.001 \\
\hline $\begin{array}{l}\text { I believe that assault weapons should } \\
\text { be banned. }\end{array}$ & 0.001 & 0.001 & 0.001 & 0.000 & 0.001 \\
\hline $\begin{array}{l}\text { I believe that there should be armed } \\
\text { officers on campus. }\end{array}$ & 0.001 & 0.001 & 0.001 & 0.000 & 0.001 \\
\hline $\begin{array}{l}\text { I believe that large capacity clips } \\
\text { should be banned. }\end{array}$ & 0.001 & 0.001 & 0.001 & 0.053 & 0.004 \\
\hline $\begin{array}{l}\text { I believe that states should be report } \\
\text { mental health status for those obtaining } \\
\text { guns. }\end{array}$ & 0.001 & 0.001 & 0.001 & 0.119 & 0.001 \\
\hline $\begin{array}{l}\text { I believe that in order to obtain a gun a } \\
\text { mental health exam should be } \\
\text { performed. }\end{array}$ & 0.001 & 0.001 & 0.001 & 0.05 & 0.001 \\
\hline $\begin{array}{l}\text { I believe that security measures should } \\
\text { be in place on campus. }\end{array}$ & 0.001 & 0.001 & 0.001 & 0.142 & 0.003 \\
\hline $\begin{array}{l}\text { I believe that the US government is } \\
\text { doing enough to address the issue of } \\
\text { gun violence. }\end{array}$ & 0.021 & 0.001 & 0.030 & 0.161 & 0.001 \\
\hline I feel safe on campus. & 0.001 & 0.001 & 0.001 & 0.060 & 0.001 \\
\hline $\begin{array}{l}\text { I believe the practice of pharmacy is } \\
\text { safe from gun violence. }\end{array}$ & 0.001 & 0.001 & 0.001 & 0.002 & 0.001 \\
\hline $\begin{array}{l}\text { I believe the practice of pharmacy in a } \\
\text { community setting is safe from gun } \\
\text { violence. }\end{array}$ & 0.001 & 0.001 & 0.001 & 0.034 & 0.001 \\
\hline $\begin{array}{l}\text { I believe the practice of pharmacy in a } \\
\text { hospital setting is safe from gun } \\
\text { violence. }\end{array}$ & 0.001 & 0.001 & 0.001 & 0.080 & 0.001 \\
\hline
\end{tabular}

\section{DISCUSSION}

The findings of this study indicated that students did not feel nervous about the possibility of gun violence on campus. Therefore, the students felt that there was no need for security measures on campus, which correlates with an earlier finding reporting that fewer than $2 \%$ of students were threatened with a gun while at college.(Miller et al., 2002; Wolfson et al., 2017)

The results of the current study that the majority of students favored a ban on assault weapons and large capacity clips concurs with previous findings that college students believed military assault weapons should be banned.(Lewis et al., 2016) Students also believed that mental health screenings should be required in order to purchase and own a gun. It is reported that increasing mental health services can help prevent gun violence.(Lewis \& Huynh, 2017)

A total of 6,905 incidents of theft in community pharmacies were reported from 2007 to 2016, with robbery $(78.2 \%)$ being the most commonly reported incident. Unfortunately some of these incidents resulted in the serious injury or loss of life for pharmacy personnel.(JG, JD, MS, \& LN, 2018) In the current study, there was a significant difference in student opinion regarding the safety of practicing in community pharmacy. The majority of them believed that the community pharmacy setting was unsafe as compared to the hospital pharmacy setting. A study of DEA data looked at thefts of pharmaceuticals in the US from 2002 through 2005 and identified 8,596 extrapolated cases across the country, of which, 83\% were from pharmacy crimes.(Pharmacy Crime A look at pharmacy burglary and robbery in the United States and the strategies and tactics needed to manage the problem, n.d.) Overall, the participants in this study were concerned about the safety in community pharmacy settings, which aligns with earlier findings. These 
results call for stringent safety measures to protect pharmacy personnel from gun violence and prevent narcotic theft.

Most respondents believed that the US government is not doing enough to address the issue of gun violence. This finding is in line with the results of another study, which indicated the dissatisfaction of students with the US government's role in addressing gun violence.(Lewis et al., 2016) The issue of gun violence is complex and deeply rooted, which is why we must take a public health approach to ensuring educational campuses and communities are safe. ("Gun Violence," n.d.)

One limitation of this study is that the survey was administered to pharmacy students at one school and the results cannot be generalized to other schools. Another limitation is the non-response bias, and that the results could have been different if the entire intended population had responded.

Student opinion about gun violence is relatively uniform in terms of avoiding public threat and ensuring campus safety. Despite student opinions being heavily influenced by recent cases of gun violence on campus, the opinions expressed varied among the personal experiences of students, their demographics, as well as their political and societal views. States, the federal government, and local law enforcement agents are on the frontline of ensuring public safety and preventing gun violence. The university administration, in collaboration with various government agencies, should create a feasible community partnership in supporting mental health and campus safety measures. Future studies should include representatives from on-campus faculty and staff and compare their opinions with those of students. Student opinions can serve as a groundwork for development of public policies aimed at reducing gun violence.

\section{REFERENCES}

Aizenman, N. (2018). Deaths From Gun Violence: How The U.S. Compares With The Rest Of The World. Retrieved July 19, 2019, from https://www.npr.org/sections/goatsandsoda/2018/11/09/ 666209430/deaths-from-gun-violence-how-the-u-s-compares-with-the-rest-of-the-world

Bergstein, J.M., Hemenway, D., Kennedy, B., Quaday, S., \& Ander, R. (1996). Guns in young hands: a survey of urban teenagers' attitudes and behaviors related to handgun violence. The Journal of Trauma, 41(5), 794-798. Retrieved from http://www.ncbi.nlm.nih.gov/pubmed/8913206

Erensen, J.G., Haddox, J.D., Attre, M.S., \& Bauza, L.N. (2018). Pharmacy-related theft of controlled substances: RxPATROL $®$ findings. Journal of Opioid Management, 14(5), 373-380. https://doi.org/10.5055/JOM.2018.0469

Gun Violence. (n.d.). Retrieved September 27, 2021, from https://www.apha.org/topics-and-issues/gunviolence

HISTORY. (2011). Virginia Tech shooting leaves 32 dead. Retrieved July 19, 2019, from https://www.history.com/this-day-in-history/massacre-at-virginia-tech-leaves-32-dead

Keneally, M. (2019). The 11 mass deadly school shootings that happened since Columbine. Retrieved July 19, 2019, from https://abcnews.go.com/US/11-mass-deadly-school-shootings-happenedcolumbine/story?id=62494128

Lewis, R.K., \& Huynh, M. (2017). Mental health provision, religion, politics, and guns: College students express their concerns. Mental Health, Religion \& Culture, 20(8), 756-765. https://doi.org/10.1080/13674676.2017.1397615

Lewis, R.K., LoCurto, J., Brown, K., Stowell, D., Maryman, J., Dean, A., ... Siwierka, J. (2016). College Students Opinions on Gun Violence. Journal of Community Health, 41(3), 482-487. https://doi.org/10.1007/s10900-015-0118-x

Mascia, J. (2019). Gun Deaths Dropped in 2018, Excluding Suicides. Retrieved July 19, 2019, from https://www.thetrace.org/2019/01/gun-deaths-2018-america-mass-shootings-suicide/

Merrill, C. (2013). White House: Now is the Time. Retrieved from http://www.documentcloud.org/documents/556943-white-house-now-is-the-time.html

Miller, M., Hemenway, D., \& Wechsler, H. (2002). Guns and Gun Threats at College. Journal of American College Health, 51(2), 57. Retrieved from https://eds-a-ebscohost- 
com.ezproxy.rosalindfranklin.edu/eds/pdfviewer/pdfviewer?vid=1\&sid=512b09d7-04bd-47a08e33-0d50aad4973e\%40sdc-v-sessmgr03

NAMI. (2019). Violence and Gun Reporting Laws. Retrieved July 19, 2019, from https://www.nami.org/Learn-More/Mental-Health-Public-Policy/Violence-and-Gun-ReportingLaws

Pharmacists Mutual Insurance. (n.d.). Company Pharmacy Crime: A look at pharmacy burglary and robbery in the United States and the strategies and tactics needed to manage the problem. Retrieved from https://phmic.com/wp-content/uploads/2017/02/415220-Crime-Report.pdf

Weller, C. (2018). These four countries have nearly eliminated gun deaths - here's what the US can learn. Retrieved July 19, 2019, from https://www.independent.co.uk/news/world/americas/gundeaths-eliminated-america-learn-japan-australia-uk-norway-florida-shooting-latest-newsa8216301.html

Wolfson, J.A., Teret, S.P., Azrael, D., \& Miller, M. (2017). US Public Opinion on Carrying Firearms in Public Places. American Journal of Public Health, 107(6), 929-937.

https://doi.org/10.2105/AJPH.2017.303712 